\title{
Understanding eco-immunology of bacterial zoonoses and alternative therapeutics toward "One Health"
}

\author{
Manisha Behera ${ }^{1,2}$ (D), Soma Mondal Ghorai² (D), Sachinandan De ${ }^{1}$ (D) and Hardeep Kaur ${ }^{3}$ (D) \\ 1. Animal Biotechnology Center, National Dairy Research Institute, Karnal, Haryana, India; 2. Department of Zoology, \\ Hindu College, University of Delhi, Delhi, India; 3. Department of Zoology, Ramjas College, University of Delhi, Delhi, \\ India. \\ Corresponding author: Soma Mondal Ghorai, e-mail: somamghorai@gmail.com \\ Co-authors: MB: beheramanisha16@gmail.com, SD: sachinandan@ndri.res.in, HK: hkaur53d@gmail.com \\ Received: 27-12-2020, Accepted: 12-03-2021, Published online: 03-05-2021
}

doi: www.doi.org/10.14202/IJOH.2021.104-115 How to cite this article: Behera M, Ghorai SM, De S, Kaur H (2021) Understanding eco-immunology of bacterial zoonoses and alternative therapeutics toward "One Health," Int. J. One Health, 7(1): 104-115.

\begin{abstract}
The current review identifies key bacterial zoonoses, the understanding of comparative immunology, evolutionary trade-offs between emerging bacterial pathogens and their dynamics on both arms of immunity. The several gaps in the literature limit our understanding of spread of prominent bacterial zoonotic diseases and the host-pathogen interactions that may change in response to environmental and social factors. Gaining a more comprehensive understanding of how anthropogenic activities affects the spread of emerging zoonotic diseases, is essential for predicting and mitigating future disease emergence through fine-tuning of surveillance and control measures with respect to different pathogens. This review highlights the urgent need to increase understanding of the comparative immunity of animal reservoirs, design of vaccines according to the homology in host-pathogen interactions, and the alternative strategies to counter the risk of bacterial pathogenic spillover to humans with eventual spread of zoonotic diseases.
\end{abstract}

Keywords: alternative antimicrobials, bacterial zoonoses, comparative immunology, One Health.

\section{Introduction}

In nature, there is a powerful adaptation and counter-adaption between hosts and pathogens due to their continual interaction to prove superior over each other in the race to evolution. Infections that get transmitted between diverse vertebrates and humans are termed zoonotic, the recipient being human, either through direct contact, food sources, or intermediate vectors. It is a complex challenge to fully understand the ecology of zoonotic diseases at the animal-human interface. A deep understanding and a thorough knowledge of ecology, immunology, microbiology, sociology, and evolution is required to understand the underlying concepts of transmission and pathophysiology of pathogens among humans, livestock, and wildlife $[1,2]$. Thus, the ancient concept of "One Health perspective" establishes that the well-being and fitness of people are inextricably linked to the health of animals and the environment [3]. For this reason, a collaborative effort involving multiple sectors and disciplines is required to tackle disease outbreaks through a "One Health" approach. One Health is not just a concept but addresses other public health issues which have become more important in recent years [2].

Copyright: Behera, et al. This article is an open access article distributed under the terms of the Creative Commons Attribution 4.0 International License (http://creativecommons.org/licenses/ by/4.0/), which permits unrestricted use, distribution, and reproduction in any medium, provided you give appropriate credit to the original author(s) and the source, provide a link to the Creative Commons license, and indicate if changes were made. The Creative Commons Public Domain Dedication waiver (http:// creativecommons.org/ publicdomain/zero/1.0/) applies to the data made available in this article, unless otherwise stated.
Changes in the environment forced many microbes to exploit alternate niches, thus looking for new hosts and posing new challenges. Understanding of the relationship between environmental changes, dynamics of wildlife population and their microbes can be used to forecast the risk of human infection with enzootic or endemic zoonoses. It has been appraised that $75 \%$ of the recent emerging diseases (e.g., swine flu, severe acute respiratory syndrome [SARS]) are zoonotic in origin [4]. Most of the emerging pathogens have a non-human intermediate host which determines the extent of the disease outbreak in humans. This risk can vary with geography, seasons, or through multiyear cycles and can depend on factors such as changes in land use, weather, climate, or environment [5]. Over the past decades, innumerable research articles have described microorganisms as zoonotic, but still, there is a looming gap about the type and intensity of contact patterns, and thus the exact transmission pathways of microorganisms from livestock to humans usually remain unclear. Moreover, most of the citations in the literature on contact intensity are based on the occupational status of the carrier or infected person with a livestock-associated (LA)-microorganism. These studies performed in an occupational setting provided minimal evidence of exposure-response relationships between the intensity of livestock-human contacts and the transmission of microorganisms. Using methods that are already in place in the exposure assessment sciences [6], exposure to LA-zoonotic microorganisms through contact patterns between livestock and humans can be better quantified both in the occupational and in the non-occupational settings. This will 
be crucial in the development of effective interventions to prevent the transmission of microorganisms from animals to humans [7].

Prediction of outbreaks and developing effective treatments largely depends on our understanding of the type of pathogen and the epidemiology of the zoonotic disease [8]. Pathogens need to adapt to the inconsistent environment and overcome a hierarchal series of immunological barriers from animals to humans [9]. To become zoonotic, pathogens should acquire new features to overcome host species barriers to successfully transmit to- and between- humans [8]. Anthropogenic land-use-change (LUC) had resulted in the emergence of pathogens, with bacteria being the most common zoonotic pathogen for mammalian hosts, followed by viruses, helminths, and protozoa. Across the globe, bacterial pathogens in animals such as rodents and livestock, viruses in bats and helminths, and protozoa in carnivores are evenly studied and documented. All types of anthropogenic LUCs considered here (i.e., deforestation and fragmentation, agricultural conversion/intensification, and urbanization) have the probability of increasing the threat of emergence of zoonotic bacterial disease. One of the major health issues among developing countries is the emergence of antibiotic resistance both in livestock and human population, for example, emergence of methicillin-resistant Staphylococcus aureus in animals and humans [10]. The indiscriminate use of antibiotics in livestock and agriculture has increased the risk of rapid outbreaks of antibiotic-resistant zoonotic emerging infectious diseases (EIDs) that could spread very quickly [11]. Despite this potentially major global issue, the link between zoonotic disease emergence and antibiotic resistance due to urbanization and agricultural intensification is not well reported in the literature.

To understand the complex ecology of antimicrobial resistance and foodborne zoonoses and how some zoonotic microbes jump to different species and proliferate, a deep knowledge of the microbiome of the people and the animals they come in contact with is required. Effects of the use of antibiotics in animal production are not well understood, and the translation of this science could be enhanced by the involvement of physicians, veterinarians, and ecologists in the design and interpretation of studies. Comprehensive data and long-term monitoring are needed for the risk assessments against multidrug resistance development in humans and animals [12-14].

This review aims at understanding antibiotic-resistant zoonotic EIDs, the eco-immunology of host-pathogen relationship, the diet that promotes healthy or protective gastrointestinal flora or probiotics, practice and use of phage-technology, bacterial cell wall hydrolases, and antimicrobial peptides (AMP) that help to reduce the need for antimicrobial use in humans and animals $[15,16]$.

\section{Comparative Immunology and Evolutionary Trade-offs}

Comparative immunology accentuates the species-level heterogeneity in immune traits and enhances our understanding of how species defend against parasites [17]. Furthermore, eco- immunology complements comparative immunology by evaluating substantial variation in immune defenses and the selective forces and constraints that influence the evolution of immunity [18]. Cost in immunity can lead to trade-offs within individuals at an evolutionary scale [19]. This understanding has led to the development of the concept of tolerance into the measures of immunity. Combining disease ecology and constraints that shape immunity, the spread of infectious disease can be predicted [20]. For instance, a lot of public concern has been raised on the rise of drug-resistant microbes leading to an "antibiotic crisis" with no suitable alternatives for antibiotics [21]. Similarly, a study shows that avian malaria (pathogen-Plasmodium spp.), when introduced to a new area, can cause rapid mortality among native birds as was seen in case of birds endemic to Hawaii, the Galapagos, and other archipelagoes [22]. Thus, the treatment should focus more on tolerance where new therapeutics should be aimed at reducing the virulence of infections rather than pathogen elimination [23]. Eco-immunology now encompasses the study of tolerance, reaching into human biomedicine, wildlife ecology, and public health. Immunity is linked to both disease transmission and infection outcomes; thus, the effect of pathogen load can directly influence host fitness and population dynamics by either directly killing the host, decreasing survival rates, or by modifying reproductive output [24].

Evolutionary costs of immunity are influenced by genetically correlated traits where some genes were noted to influence immune phenotypes and also regulate other traits that are inherited with other genes [25]. Consequently, contradictions are present between traits that enhance fitness and the traits that promote immunity [24]. Another correlation is seen between comparative immunology and community ecology of infectious diseases. The spread of the same pathogenic infection among multiple species can provide information on heterogeneity in host immunity and can lead to development of certain models that could predict spread of infectious diseases [20]. Thus, incorporating ecological factors and organismal traits into comparative studies of immunity can provide insights into both the evolution of immune defenses and community-level consequences of cross-species variation in immunity.

\section{Bacterial-dynamics among Different Arms of Immune System}

Bacterial zoonoses are an EID of global importance. These diseases are mostly passed onto humans either through oral consumption of infected animals, 
direct contact with infected animals, or through insect vectors. They are among the most neglected pathogens studied despite the huge amount of data on their incidence and prevalence as a predominant cause of acute febrile illness (Table-1). Thus, little is understood about zoonotic bacterial pathogenesis and host immune responses. Much interest on zoonotic pathogenesis has recently gathered competence and among the most studied are the five distinct infections, namely; salmonellosis, leptospirosis, relapsing fever borreliosis and rickettsiosis (including scrub typhus, and murine typhus), and spotted fever group rickettsiosis; which are globally distributed acute febrile diseases, and have high rates of morbidity and fatality [26].

Although being asymptomatic, animals can still serve as natural hosts for zoonotic diseases. Leptospirosis is the most extensively studied zoonotic disease which is passed on to humans after exposure to mucous membranes and abraded skin of infected animals [27]. Leptospirosis stimulates bacterial lipopolysaccharide (LPS) and lipoproteins by binding to toll-like receptor-2 (TLR), causing heightened pro-inflammatory response, and developing disseminated intravascular coagulation with multi-organ failure. Likewise, pulmonary hemorrhage is quite recurrent in affected persons with increased antibody titers, and there is evidence that immunoglobulin and complement fixation in host cells are related to the expression of specific leptospiral hemostatic proteins [28]. It was also noted that the "immune" phase correlates with increased immunoglobulin titers and complement deposition leading to the late occurrence of leptospiral uveitis [29]. Most of the reports on leptospirosis show how this pathogen modulates the host innate immune response through TLRs or through surface-exposed proteins [30].

Indeed, marked variations and diversity exist between different classes within pattern recognition receptor (PRR) structure. It reflects the potential threat that each species encounter, which instill evolutionary pressure bringing in subtle differences within the innate immune system. Surprisingly, the selective pressure that brings in diversity seems to be non-existent in the laboratory strains of murine sequences; perhaps due to the intensive inbreeding of mice [31]. Nevertheless, PRRs in humans show a higher degree of sequence homology to livestock, rather than their murine counterparts. The similarity between human and livestock PRR is further supported by their similar response to some microbial-associated molecular patterns (MAMP), such as lipopeptides, bacterial LPS or small synthetic ligands, whereas species differences have been reported for the detection of these MAMP between murine and other mammalian PRR [32]. This makes it clearer that the innate immune response in different vertebrates is non-identical. In the wild, reptiles also revealed subtle variations in TLRs selection constraints as they fine-tune the recognition ability of the host TLRs to respond to their respective ligands

Table-1: List of zoonotic bacterial pathogenesis, source, and carrier host.

\begin{tabular}{|c|c|c|c|c|}
\hline Disease/Common Name & Causative bacteria & Pathogen source & Wildlife source & Host/Reservoir \\
\hline $\begin{array}{l}\text { Brucellosis/Mediterranean } \\
\text { fever, Malta fever, gastric } \\
\text { remittent fever, and } \\
\text { undulant fever }\end{array}$ & $\begin{array}{l}\text { Brucella spp. (e.g., Micrococcus } \\
\text { melitensis) }\end{array}$ & $\begin{array}{l}\text { Milk, after birth, } \\
\text { lymph nodes }\end{array}$ & $\begin{array}{l}\text { Bison, elk, } \\
\text { gazelles }\end{array}$ & $\begin{array}{l}\text { Camels, horse, } \\
\text { Ruminants }\end{array}$ \\
\hline Mycobacteriosis/Tuberculosis & Mycobacterium tuberculosis & Aerosols & $\begin{array}{l}\text { Badgers, } \\
\text { white-tailed deer, } \\
\text { gazelle }\end{array}$ & $\begin{array}{l}\text { Ruminants, } \\
\text { camels, other } \\
\text { mammals }\end{array}$ \\
\hline Anthrax & Bacillus anthracis & $\begin{array}{l}\text { Animal blood, } \\
\text { spores in soil }\end{array}$ & Mammals & $\begin{array}{l}\text { Warm-blooded } \\
\text { animals }\end{array}$ \\
\hline Chlamydiosis/chlamydia & Chlamydia trachomatis & Aerosols & $\begin{array}{l}\text { Psittacine, falcon, } \\
\text { pigeon, other } \\
\text { birds }\end{array}$ & $\begin{array}{l}\text { Mammals, sheep, } \\
\text { goat, camels }\end{array}$ \\
\hline Q-fever & Coxiella burnetii & Aerosols, raw milk & Rats, pigeon & $\begin{array}{l}\text { Livestock, cows, } \\
\text { goat, camels }\end{array}$ \\
\hline Salmonellosis/Typhoid fever & $\begin{array}{l}\text { Bacteria of the family } \\
\text { Enterobacteriaceae. (Salmonella } \\
\text { enterica and Salmonella bongori) }\end{array}$ & $\begin{array}{l}\text { Feces, blood, } \\
\text { tissue }\end{array}$ & Pigeons, birds & $\begin{array}{l}\text { Poultry, } \\
\text { mammals }\end{array}$ \\
\hline $\begin{array}{l}\text { Leptospirosis/mud fever; fall } \\
\text { fever }\end{array}$ & genus Leptospira & $\begin{array}{l}\text { animal urine, and } \\
\text { contaminated soil } \\
\text { or water }\end{array}$ & Rodents & Humans \\
\hline Borreliosis/Lyme disease & $\begin{array}{l}\text { Borrelia burgdorferi } \\
\text { Borrelia mayonii }\end{array}$ & blood & Blacklegged ticks & $\begin{array}{l}\text { Humans, } \\
\text { mammals }\end{array}$ \\
\hline $\begin{array}{l}\text { Rickettsioses/Spotted fever, } \\
\text { scrub typhus fever }\end{array}$ & $\begin{array}{l}\text { Multiple bacteria from the order } \\
\text { Rickettsiales and genera Rickettsia } \\
\text { (R. rickettsii } \\
R . \text { prowazekii, etc.) }\end{array}$ & Blood, tissues & $\begin{array}{l}\text { Arthropods } \\
\text { (hematophagous } \\
\text { insects and ticks) }\end{array}$ & $\begin{array}{l}\text { Humans, } \\
\text { mammals }\end{array}$ \\
\hline Mastitis/Cystic fibrosis & Pseudomonas spp. & $\begin{array}{l}\text { Raw milk, chicken } \\
\text { meat }\end{array}$ & Livestock, poultry & Cattle, humans \\
\hline Staph infection & Staphylococcus aureus & $\begin{array}{l}\text { Contaminated } \\
\text { milk, aerosols }\end{array}$ & $\begin{array}{l}\text { Livestock, } \\
\text { humans }\end{array}$ & Humans \\
\hline
\end{tabular}


from the pathogen profile in their niche, rather than conferring the ability to recognize a new ligand altogether. Although genetic events like gene gain and gene loss are also responsible for shaping the TLR repertoire in vertebrate classes, these processes are constant and gradual and usually affect a broader phylogenetic unit than just a family or order [33].

Other studies on genome sequences illustrate that most of the other bacterial infection such as relapsing fever borreliosis, scrub typhus, murine typhus, and spotted fever rickettsiosis are caused due to adaptation to an obligatory intracellular lifestyle, through the loss of genes and pathways, required for extracellular growth [34,35]. A case-control study on bovine translational genomics employing validated variants from bovine TLR genes recognized bacterial ligands and revealed six single nucleotide polymorphisms (SNPs) potentially eliciting small effects on susceptibility to Mycobacterium avium spp paratuberculosis infection in dairy cattle [36]. Surprisingly, not much work is done on the immunological aspects of these diseases. Recently, five SNPs, namely, TLR 1 (+1380 G/A), TLR1 (+1446 C/A), TLR4 (+10 C/T), TLR9 (+1310 G/A), and Solute Carrier Family 11 Member 1 (SLC11A1) $(+1066 \mathrm{C} / \mathrm{G})$ have been found to be associated with paratuberculosis susceptibility in cattle which is currently considered as potential zoonoses, causing Crohn's disease in humans [36,37]. Similarly, TLR5 and TLR11 are found to be associated with Salmonella infection with some ambiguity within TLR2 and TLR4 [38].

Streptococcus equi subsp. zooepidemicus is known to be infectious not only in horses but also in other mammals, including humans. Heat-inactivated $S$. equi was shown to induce a powerful and defined cytokine/chemokine response accompanied by induction of a panel of transcription factors/signaling molecules and this response is strongly dependent on TLR2 and on cell-cell contacts between bacteria and mast cells. Zheng et al. [39] have shown Streptococcus suis recognize TLR2/TLR6 and TLR9 and mediates the release of pro-inflammatory mediators. Interactions of lipoproteins with TLR6 likely increase the activity of NF-kB [39]. In another study, TLR6 was shown to downregulate Streptococcus zooepidemicus infection in the presence of SzP (M-like protein), which likely increases pathogenesis of $S$. Zooepidemicus by inhibiting the host immune response, in addition to its escape from phagocytosis [40].

Mastitis caused by Pseudomonas, an inflammatory disease of the mammary gland generally caused by intramammary infections, is the most frequently occurring disease in the dairy industry. In the bovine genome, there are 10 TLR family members and, of these, TLR2, TLR4, and TLR6 are specialized in recognition of bacterial ligands [41]. Pseudomonas, an opportunistic infectious agent in humans, infect through LPS and flagellin, recognized by TLRs 2 , 4 , and 5 [42]; but its prevalence and correlation with
TLRs are yet to be established among chickens [43]. Some in vivo and in vitro studies that were done in poultry infected with Mycoplasma gallisepticum and Salmonella enteritidis have shown significant upregulation of TLR2-1 (TLR2 type 1 precursor) [44].

Studies have also revealed the prevalence of Salmonella and Escherichia coli in neonatal diarrheic calves [45]. LPS-TLR4 signaling plays an essential role in the generation of both innate and adaptive immune responses throughout the course of infection with Salmonella in mice [46]. TLR-4 is an important candidate gene for imparting disease resistance in livestock as it is involved in pathogen recognition in most of Gram-negative bacterial infections that lead to the initiation of the inflammatory and immune responses. There is a single report where the unfavorable alleles at P-226 (putative promoter region) and E3+1656 (Exon 3) of TLR-4 SNPs if removed, can result in disease-resistant bovines [47]. Identification of non-synonymous SNPs and novel variants of TLR2, TLR4, and TLR6 genes were recently established which helped in identifying disease-resistant breeds of European cattle. The genotypes which conferred resistance to both disease and adverse environmental conditions usually had variants in the introns rather than in the exons of TLRs, which are fairly conserved [48]. TLR5 recognizes bacterial flagellin ligand and exhibits a range of immunological effects on the chicken immune system and elicits a mixed Th1 and $\mathrm{Th} 2$ response, though with an inclination toward a Th2 response [49].

Salmonella spp. infection has been associated with heavy losses on a broiler farm. Innumerable food poisoning outbreaks due to Salmonella in chicken, clearly states that Salmonella is a major zoonotic pathogen but still immune relevance of the disease in context to TLRs has not been studied. It is quite evident that like humans, the animals for commercial use have undergone a massive evolutionary selection pressure to survive under similar novel pathogenic environments. The human cultural and economic needs have shaped tremendous immunogenic variation in TLRs within the cattle and poultry population. For instance, TLRs in chicken are more diverse than human TLRs, which forms the genetic basis of breed-specific variation in resistance to various infectious diseases. Computational and structural studies revealed that the structural basis of host-specific TLR response was found to be conserved in almost all vertebrate classes. Some of the interactions in different species were found to be consistent with the crystal structure of Salmonella fliC gene (flagellin gene that encodes major component of flagellum) and also to Bacillus subtilis hag flagellin indicating the evolutionarily conserved nature of TLR5 binding with flagellin while differences in some interacting residues may be responsible for host-specific response, thus providing awareness into the evolution of species-specific host-microbe interactions 


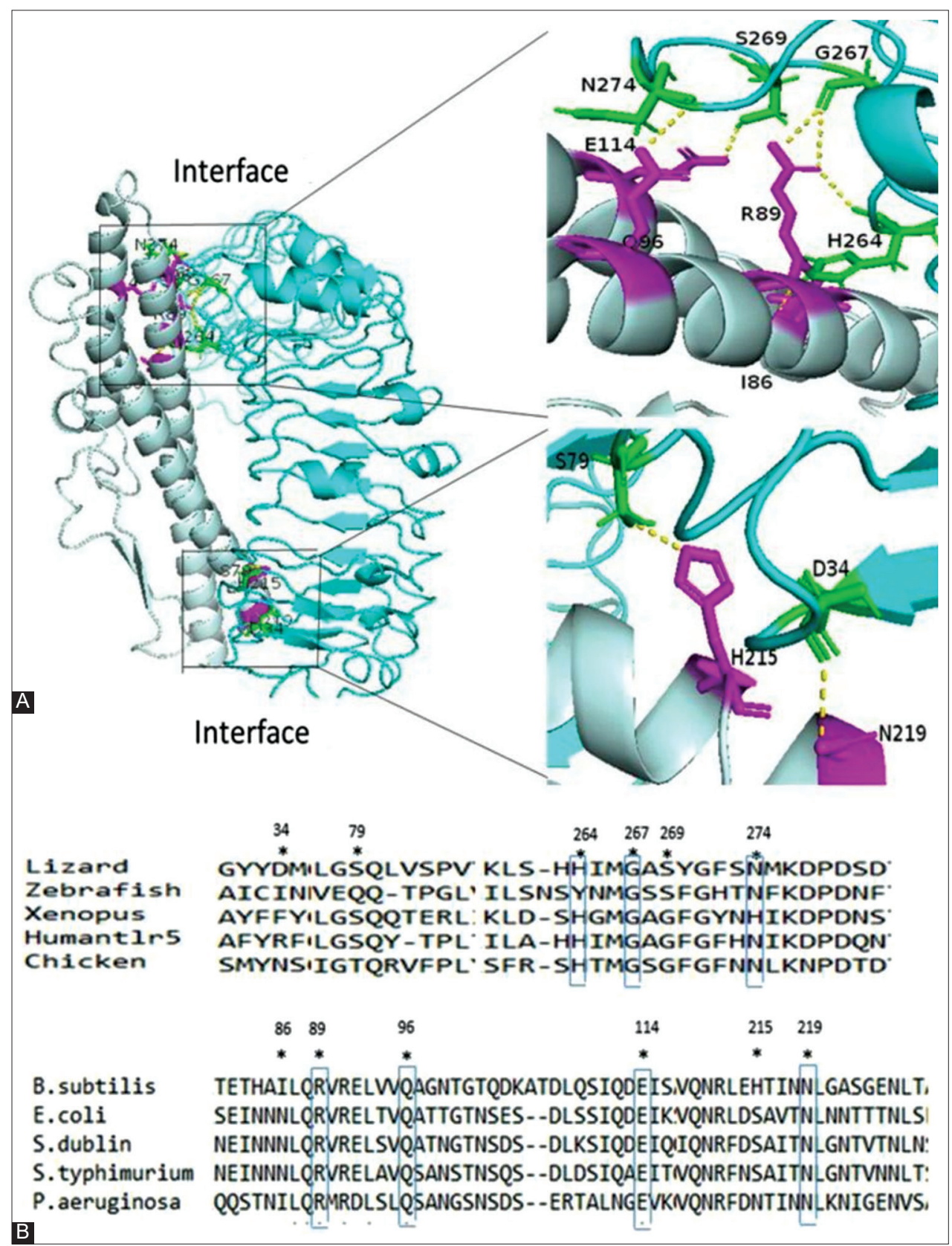

Figure-1: Presence of hydrogen bonds at binding interfaces of TLR5- Bacillus subtilis flagellin complex (TLR5, green; bsflagellin, pink). (A) Alignment of residues of TLR5 ligand-binding domain involved in $\mathrm{H}$-bonds (conserved residues are seen in different vertebrates), (B) alignment of residues of flagellin involved in binding (conserved residues are seen in different bacterial species) [Source: Figure prepared by the authors].

(Figure-1) [50]. An insight into the informatics of both the pathogen and the host/carrier can help evaluate protein dynamics of the pathogen-receptor confluence and may pave the way for future vaccine design catering to a wide group of vertebrates. This can be explained using Immunoinformatics where one can identify the epitopes which may help predict the tertiary structure of the protein that completely docks with the respective PRRs. Finally, molecular dynamics simulation can help evaluate the stability of vaccine molecule and PRR-vaccine complex, thus leading to the development of a novel multi-epitope vaccine that is able to induce cellular, humoral, and innate immune response against a wide range of bacterial zoonoses (Figure-2).
Coinfection with bacterial pathogen has significant effects on other disease dynamics at the population level as observed in Mycobacterial infection which gets accentuated with helminths infestation in cattle [51]. Key signaling molecules like cytokines are responsible for changing the dynamics of coinfection resulting in significant trade-offs within Th1/Th2 immune responses. Cytokines like interferon-gamma are responsible for simultaneously enhancing one response while suppressing the other. They enhance Th1 response that favors bacterial infection whereas downregulates $\mathrm{Th} 2$ type responses responsible for targeting parasitic infection [52]. Cytokine structure and function are pretty conserved throughout host-pathogen interfaces [53]. Therefore, they have a critical role 


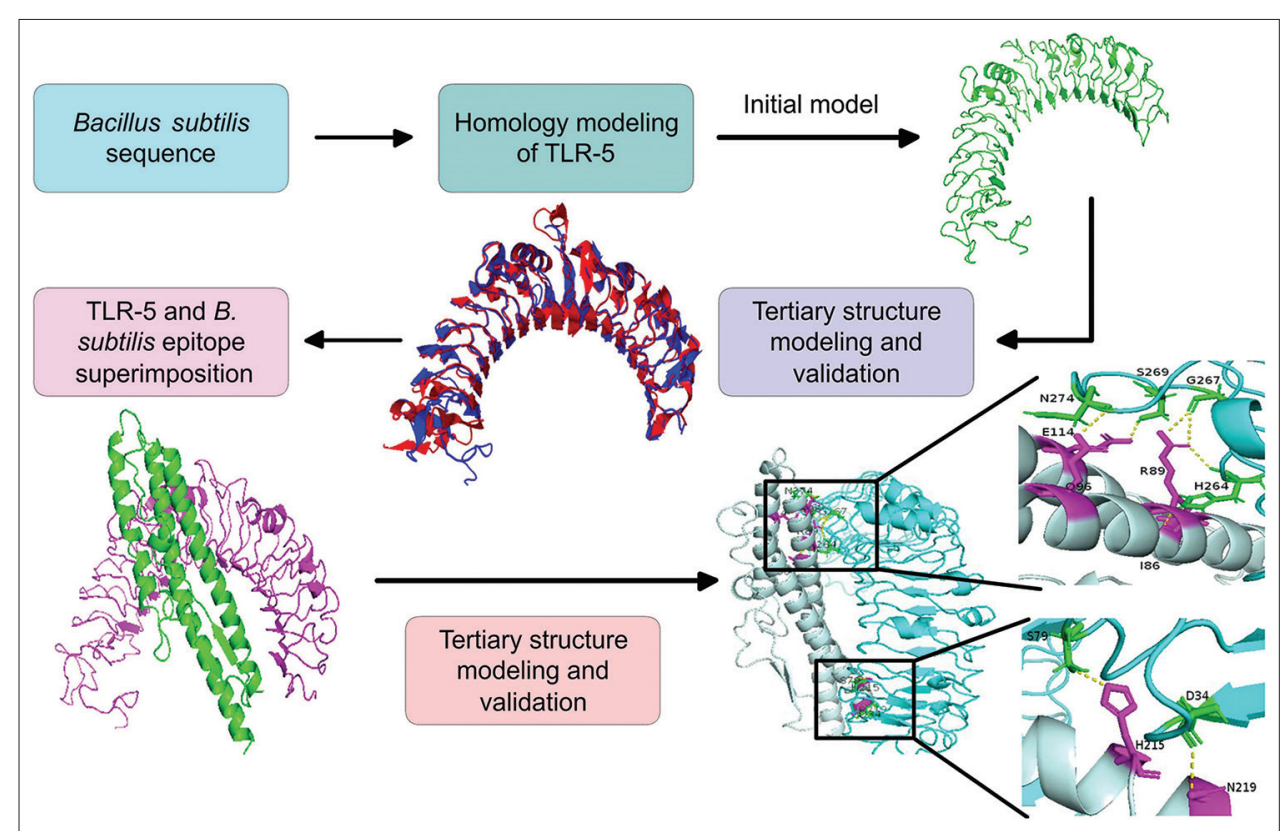

Figure-2: Schematic representation of protein modeling of the epitopes with pattern recognition receptors to generate suitable ligands for vaccine development for potential bacterial zoonoses [Source: Figure prepared by the authors].

in mediating immune trade-offs and coinfection outcomes. Moreover, cytokines can be easily measured at any point of infection, thus making them a useful tool for future studies at the interface of ecological immunology and disease ecology [51].

\section{Alternatives to Antimicrobials Toward "One Health"}

"Multidrug-resistant pathogens" is the new buzzword in the world of infectious diseases and is usually dominated by zoonotic pathogens such as methicillin-resistant Salmonella typhimurium, S. aureus, and Pseudomonas aeruginosa. These bacterial strains are directly correlated with a significant disease burden in veterinary medicine, agriculture, livestock production, and regional and national economies. Sadly, majority of zoonotic bacterial and viral infections draw unreasonably less scientific and public health interest, especially with regard to their lifecycles in vertebrate animals that act as pathogen reservoirs. Thus, understanding their burden may allow for improved vigilance and interception measures [54]. In this section of the review, a systematic evaluation of promising future therapeutics to the known bacterial zoonoses is discussed with emphasis on alternatives to antimicrobial resistance such as the AMP, phage therapy, LPS inhibitors, and efflux pump inhibitors that are widely used to control multidrug-resistant pathogens.

\section{Protective Diet for Gastrointestinal Flora}

A good amount of literature is available that shows that our gut microbiome has a strong effect on our well-being. It impacts many human diseases, including cardiovascular diseases, obesity, skin disorders, autism, and even affects human psychology [55]. A diet comprising carbohydrates, proteins, fats, probiotics, and polyphenols are responsible for the shift in dynamics of our gut microbiome. Although the human gut predominantly comprises the Gram-positive Firmicutes and Gram-negative Bacteroidetes [56], a certain diet pattern may change the equation of the microbiome with secondary effects on host immunology and metabolism. Studies have shown that a high protein diet decreases bacteria of the group Roseburia/Eubacterium rectale, while increasing the abundance of bile-tolerant organisms such as Bacteroides, Alistipes, and Bilophila. High fat intake did not cause any significant change in microflora abundance but few reports have shown that a highfat diet adversely reduces Akkermansia muciniphila and Lactobacillus, both of which are associated with a healthy metabolism. There is evidence that a carbohydrate-rich diet enriches anaerobes such as Bifidobacterium, Lactobacillus, Ruminococcus, E. rectale, and Roseburia; but suppresses Clostridia. Bifidobacterium and lactic acid bacteria get enhanced with Probiotics and polyphenols intake, while reducing enteropathogenic Clostridia species [55].

Intestinal microbiota is known to affect immunity through the expression of TLRs, antigen-presenting cells, B- and T-lymphocytes, and lymphoid follicles [57]. Gut microbiome may have both deleterious and healthy consequences on the immune system. For instance, lactic acid bacteria and Bifidobacteria have a dampening effect on inflammation by downregulating NF- $\mathrm{kB}$ dependent gene expression, thereby decreasing the cytokine (interleukin-8) secretion. Both these bacteria also downregulate $\mathrm{T}$ effector-mediated inflammatory responses while enhancing anti-inflammatory T-regulatory cell expression [58]. Few filamentous bacteria are documented to promote Th17 response and cause autoimmune arthritis [59]. Thus, balanced 
gut flora is critical for a healthy immune system; though the mechanism by which the gut microbiome influences immunity is still not clear. A few studies have suggested that the microbial-derived short-chain fatty acid may increase the abundance of T-regulatory cells through G-protein-coupled receptor and epigenetic mechanisms. Moreover, the microbial-derived butyrate is shown to inhibit histone deacetylases 6 and 9 , leading to increased acetylation in the promoter of the FOXP3 gene and causing T-cell proliferation [60].

Recent advances in microbiome research offer exciting avenues to enhance human health. Many diseases such as ulcerative colitis, Clostridium difficile-associated colitis, irritable bowel syndrome, and even obesity can be managed by re-engineering the gut microbiota. Techniques such as the shotgun metagenomics approach can be employed to sequence the whole bacterial genome which may help in investigating human and bacterial interactions. Novel therapeutic approaches for many diseases with strong genetic associations are the next big thing for personalized medicine. Indeed, metabolic responses to meals can be predicted through the emerging concept of the machine-learning algorithm where a greater variety of food components would be helpful in making specific dietary recommendations to patients.

\section{Phage-technology as Effective Antimicrobials}

The use of bacteriophages in controlling bacterial infections represents the most promising therapeutic option. Bacteriophages are bacterial viruses that act against bacteria. Phages were first discovered by Frederick Twort in 1915 and Felix d'Herelle in 1917; and were used to treat infections such as dysentery and cholera. The Eliava Institute of Bacteriophages, Microbiology and Virology in Tbilisi, Georgia which has been treating patients using phage therapy for nearly 100 years, is currently using it to treat infections caused by Carbapenemresistant Enterobacteriaceae and other resistant bacteria. Most of the known phages show lytic cycle, by which they lyse or hydrolyze the bacterial cell to release their progeny. Other phages are lysogenic in nature as they do not kill the bacterial cell and incorporate their genome into bacterial genome and exist in the form of prophage. Phages have the ability to kill bacterial cells at the end of infection process. It has been studied that bacteria show very less resistance toward the bacteriophage as compared to antibiotics. As an antimicrobial, phages show more advantages as compared to antibiotics, since antibiotics get degraded through metabolic reactions and generally require repeated administrations. In case of phages, their increasing titer during different period, removes the need for repeated doses. In addition to this, they shows high specificity for a particular host bacterium and do not affect the commensal intestinal micro-flora which is generally killed by antibiotics. Bacteriophages are species-specific or even strain-specific and the success of phage therapy is dependent on the phage and bacterial interactions, but sometimes off-target results can also take place due to the broad host range of phages. However, this effect is significantly less than the effects of antibiotics on commensal flora. The higher growth rate of bacteriophage generally overcomes bacterial growth. The use of phage therapy can be applied to prevent bacterial infections in veterinary animals. Bacteriophages are used to prevent foodborne infections as the bacteriophage-derived product such as endolysin is used in detecting as well as reducing microbial load in packaged food. Example includes LMP-102, which is used as food additive in meat and poultry products and acts as antibacterial agent against Listeria monocytogenes [61].

Nowadays, endolysins are generally used to control antibiotic-resistant pathogenic bacteria. Virulent bacteriophages can be used against pathogenic bacteria as phage cocktails (phage therapy) or phage lytic proteins such as endolysins and virion-associated peptidoglycan hydrolases. These are phage-encoded enzymes that break down peptidoglycan component of the bacterial cell wall at the end of phage reproduction cycle. Bacteriophage endolysins (peptidoglycan hydrolases) are secreted by double-stranded DNA phages at the end of the lytic lifecycle for the release of mature phage progeny. The ssDNA phages synthesize a single lysis gene to get out of host bacteria or secrete a protein that inhibits cell wall biosynthesis in the host. Besides this, there is a pinholin system in some dsDNA phages where signal-arrest-release (SAR) endolysin secreted by the host's pathway causes cell lysis. In this pathway, endolysin has a signal anchor release that guides its pathway to the peptidoglycan layer and the role of pinholin is to change the permeability of the layer. Until SAR endolysin reaches periplasma, its catalytic domain is locked in an inactive form [62]. The mechanism followed by dsDNA phages at the end of lytic cycles makes the peptidoglycans produced by phages potential candidates to act as antimicrobials. At the end of the lytic lifecycle, dsDNA phage encodes holin and endolysin proteins to lyse the bacterial cell wall and additional spanning protein in the case of Gram-negative bacteria to break the outer membrane. Exebacase (also called as CF-301) and N-Rephasin SAL200 (tonabacase) are the lysins used for the treatment of bacterial infections $[63,64]$. In addition, it has been found that bacteria show no resistance to endolysins due to their mechanism of action and their structure [65]. Endolysin is late transcriptional proteins and keeps on accumulating in the cytoplasm but since it is devoid of signal peptide it requires holin protein to complete its action [66]. Holin protein is genetically programmed in a manner that on reaching its threshold level, it arranges the monomers into oligomers to form a pore in the inner membrane, and helps endolysin to access the peptidoglycan layer. This break in the peptidoglycan 
layer causes osmotic lysis and death of the bacterial cell. Another case where inactivated endolysin is transferred to the periplasm and later holin activates, is seen in LytA amidase of Streptococcus species [67].

Phage cocktail and phage-derived endolysin has found great use in preventing surgical site infection, for instance, in hospital-acquired infection or infection acquired during surgery or transplantation. Patients infected with multidrug-resistant $P$. aeruginosa after lung transplantation showed successful recovery through single lytic bacteriophage use during treatment. BioPhage-PA has been tested in clinical trials for topical treatments against $P$. aeruginosa ear infections. Trials are also considered for aerosol form in patients suffering from cystic fibrosis. Bacteriophage treatment was able to cure a pulmonary infection caused by multidrug-resistant $P$. aeruginosa in patients with cystic fibrosis [68]. As Mycobacterium grows inside the alveolar macrophage, it is difficult for bacteriophage to access the pathogen. However, use of another avirulent Mycobacterium such as Mycobacterium smegmatis to deliver the lytic phage inside the alveolar macrophage may be the best possible mechanism to treat multidrug-resistant Mycobacterium tuberculosis [69]. Therefore, bacteriophage treatment could be an efficient treatment option for multidrug-resistant tuberculosis. A phage cocktail, BFC-1 contains phages specific for $P$. aeruginosa and $S$. aureus strains, and is used for the cure of burn wounds. Phage therapy shows great potential to overcome persistent infections that are mediated through biofilm formation and are very difficult to eradicate with antimicrobial agents. It has been studied that biofilm formation is an important factor in the pathogenesis of bacteria, especially those that are involved in persistent long-term infections. Exopolysaccharide plays a crucial role in the formation of biofilm and acts as a barrier for the penetration of therapeutic agents. Phages that have the ability to degrade these substances are useful to control bacterial infections. Phages have very narrow specificity, due to which phage therapy requires diagnostic measures to identify infecting agents. Another major aspect of phage therapy is the lack of data regarding its efficacy and pharmacokinetics. Some phages target multiple species or genera while most of them are highly specific for single strain [70]. Single phages are highly predisposed to resistance development and are generally combined into multiple phage cocktails to achieve synergy and can also be administered with small-molecule antimicrobial compounds.

\section{Antimicrobial Peptides}

AMP are also called as host defense peptides and are found in various life forms from microorganisms to humans. They are widely used as alternatives to antibiotics. Most of the AMP are cationic in nature. They are generally short, containing $<100$ residues and are amphiphilic in nature [71]. This property allows them to bind and insert themselves into membrane bilayer to form pores. The function of AMP can be altered by changing the amino acid composition, size, and cationic charge. Cationic peptides contain residues such as arginine and lysines [61]. These residues interact with the negatively charged bacterial cell surface. Peptide modification and its delivery technologies are studied to overcome various problems such as pharmacokinetics, bioavailability, and toxicity. Several methods have been employed to alter the peptide length and amino acids to study its antimicrobial activity. For this study, computer-assisted AMP design is very important to determine the biological activity of AMP. Many strategies are adopted for the delivery of these AMP such as hydrogels, liposomes, nanospheres, nanocapsules, carbon nanotubes, and DNA cages. These strategies provide enhanced antimicrobial properties and protect AMP from metabolic degradation. Besides, antimicrobial activity, AMP carries the immunomodulatory properties which makes them an important candidate in the development of new therapeutic agents. Many of them are produced as inactive precursors and require proteolytic cleavage to become active. AMP are classified on the basis of their secondary structure such as alpha helical, beta sheet, or peptides containing extended/random coil structures. Magainins are the most studied AMP and are obtained from the frog. AMP of prokaryotic origin are called as "bacteriocin." Nisin is a commonly used bacteriocin for food preservation $[72,73]$. The broad-spectrum activity and rapid mode action of AMP make them promising drug candidates to control bacterial infections. It has been reported that development of resistance against AMP is found to be very less. Pexiganan is a synthetic ana$\log$ of magainin, commonly used in the topical treatment of diabetic foot ulcers, while omiganan is used for the treatment of catheter related infections.

\section{LPS Inhibitors}

The LPS layer in Gram-negative bacteria act as a protective barrier. It inhibits the entry of antibiotics and other toxic compounds that show the ability to kill bacterial cells. LPS inhibitor works by inhibiting 3-deoxy-D-manno-octulosonicacid 8-phosphate synthase (a class of KDO8-p synthase) which is an important enzyme in the biosynthesis of LPS [74]. The RegIII (regenerating gene family protein III) family of intestinal C-type lectins is antibacterial protein that act as important LPS inhibitors in Gram-negative bacterial strains [74].

\section{Antibacterial Compounds}

Bacterial biofilm formation on medical devices such as catheter and other implanted devices is considered to be the main reason for the prevalence of infections. The growth of bacteria on devices such as urinary catheters and ureteral stents, may not only lead to infection but also to a phenomenon called as encrustation. Urease enzyme hydrolyzes the urea present in the urine and results in the elevation of $\mathrm{pH}$, 
ultimately leading to precipitation of salts and deposition of crystals on the surface. Encrustation may leads to blockage of a catheter and further cause severe complications. The bacteria most commonly associated with infections on medical devices are Staphylococcal spp. However, in urinary devices, Gram-negative bacteria (E. coli, P. aeruginosa, Enterobacter aerogenes, Klebsiella spp., and Proteus spp.) are the most common pathogen resulting in encrustation. Efforts have been made to develop medical devices with antibacterial coatings. Polymeric compounds are generally used for this purpose. The most commonly used material in antibacterial coating contains silver as one of the components. Silver shows a broad range of antibacterial activity towards both Gram-positive and Gram-negative bacteria [75].

\section{Phytochemicals}

Phytochemicals are secondary metabolites produced by the plants for defense purposes. These compounds provide protection from insects, herbivores, and microorganism. Phytochemicals include phenols, essential oils, alkaloids, proteins, and peptides that exhibit potent antimicrobial activities. Berberine is a hydrophobic cation found in barberry plants (Barberis species). One of the newly identified compound 4-[N-(1,8naphthalimide)]-n-butyric acid showed activity against the Vibrio cholera transcriptional regulator ToxT [61].

\section{Bacterial Biofilm Eradication Agents}

Biofilm formation is a predominant virulence mechanism in the pathogenesis of bacterial infections. Biofilm is a community of microorganism adhering to surface and encased in a protective polysaccharide substance. The extrapolymeric substance of biofilm is composed of proteins, lipids, and nucleic acids. LL-37 is an AMP that exhibits the potential for biofilm eradication. LL-37 is a human cathelicidin-derived broad spectrum AMP and is amphipathic in nature. In a study, it has been reported that LL-37 is able to eradicate $P$. aeruginosa biofilm in an in vivo animal model at a concentration of $556 \mu \mathrm{M}$ [76].

\section{Bacterial Cell Wall Hydrolases (BCWH)}

$\mathrm{BCWH}$ are the enzymes that degrade bacterial cell wall component peptidoglycan and leads to bacteriolysis. Lysozymes are BCWH of eukaryotic origin, produced by plants and animal cells. Autolysins are membrane-bound proteins and bacterial encoded BCWH. Virolysins are BCWH that are encoded by double-stranded DNA phages. These are generally produced by viral infected bacterial cells at the end of phage lytic cycle. BCWH exhibits bactericidal mechanism due to lytic enzymatic activity of the enzyme. They are more efficient against antibiotic-resistant bacteria as compared to antibiotics. Lysozymes are broad-spectrum lytic enzymes and are more effective against Gram-positive bacteria. However, lysozymes are nonfunctional against Gram-negative bacteria as these bacteria contain outer membrane [16].

\section{Future Perspectives}

The recent emergence of zoonotic viral disease (coronavirus disease [COVID 19] due to SARS coronavirus 2) is one of the many examples where social and environmental factors have played a major role in their widespread dispersal. These new strains have a common link of being spillover between two or more species and it is at this stage of emergence of more virulent strains that scientific interventions are of prime importance. Nearly $75 \%$ of emerging infections or pathogens including viruses, parasites, bacteria, and fungi have their origin in animals. The need of the hour is not to consider environment, animal reservoirs, and humans separately but as a whole unit, thus uplifting the "One Health" concept and develop action plans accordingly. There is still a looming gap in the proper understanding of new animal production systems and human population dynamics. Although, much improvement is achieved with regard to their surveillance system, an integrated approach for better communications and relations between agricultural sectors, environmental, and human health is vital for accurate prevention of disease appearance and transmission [77]. The current pandemic of COVID 19 has made us realize that assessment of hot spots for pathogen transmission should provide the strategy to map animal habitats that are at more risk of causing zoonotic disease spread and might serve as a mixing vessel and as the source of infection for humans [78]. The aim of this review article is to cover all fields related to bacterial zoonoses, including basic and applied researches, approaches to control disease spread, and explanations of new theories or observations. In this article, a holistic and integrative approach is taken to discuss the "One Health" strategies. Stress should be placed on the collaborative efforts of researchers specialized in different fields such as medical and veterinarians professionals, zoologists, entomologists, parasitologists, virologists, ecologists, microbiologists, evolutionary biologists, and medicals specialized in epidemiology, public health, and animal health. The participation of multidisciplinary approach can only fill in the lacunae with the knowledge that demand extensive scientific and medical interest.

\section{Conclusion}

COVID-19 has been the wake-up call for the global understanding of the impact of zoonosis and its related public health issues, though limited studies are available around this subject, mainly in developing countries. Moreover, inadequate and inappropriate policies usually delineate veterinary studies with public health concerns. In today's times, priority must be given to understanding and discussing trade-offs between the risk and impact of zoonotic hazards and local health. Thus, more research is needed on livestock and public health issues, with an emphasis on zoonotic pathogens that are sub-clinically carried by 
livestock, but that cause a significant health burden in people. Low-income countries in the Indian subcontinent and Africa usually have a constraint in the accessibility of the literature, research on disease impacts and its control. It is therefore imperative that research on topics of relevance in "One Health" must be published in open access journals. Similarly, efforts should be made to provide access to journals and databases globally and Governments should grant effortlessly towards Policy-oriented research, and allocating public funds for Veterinary public health research.

\section{Authors' Contributions}

MB and SMG conceived the design of the review and drafted the manuscript. SD and HK: Reviewed and revised the manuscript. All authors read and approved the final manuscript.

\section{Acknowledgments}

The authors express gratitude to the Principal, Hindu College, University of Delhi, for constant encouragement. MB acknowledges Council of Scientific and Industrial Research (CSIR) for financial support in the form of Junior Research fellowships.

\section{Competing Interests} interests

The authors declare that they have no competing

\section{Publisher's Note}

Veterinary World (Publisher of International Journal of One Health) remains neutral with regard to jurisdictional claims in published institutional affiliation.

\section{References}

1. Coker, R., Rushton, J., Mounier-Jack, S., Karimuribo, E., Lutumba, P., Kambarage, D., Pfeiffer, D.U., Stärk, K. and Rweyemamu, M. (2011) Towards a conceptual framework to support one-health research for policy on emerging zoonoses. Lancet Infect. Dis., 11(4): 326-31.

2. Karesh, W.B. and Cook, R.A. (2005) The human-animal link. Foreign Aff., 84(4): 38-50.

3. Asokan, G.V. (2015) One Health and zoonoses: The evolution of one health and incorporation of zoonoses. Cent. Asian J. Glob. Health, 4(1): 139.

4. Gibbs, E.P. (2005) Emerging zoonotic epidemics in the interconnected global community. Vet. Rec., 157(22): 673-679.

5. Karesh, W.B., Dobson, A., Lloyd-Smith, J.O., Lubroth, J., Dixon, M.A., Bennett, M., Aldrich, S., Harrington, T., Formenty, P., Loh, E.H. and Machalaba, C.C. (2012) Ecology of zoonoses: Natural and unnatural histories. Lancet, 380(9857): 1936-1945.

6. Basinas, I., Schlünssen, V., Takai, H., Heederik, D., Omland, Ø., Wouters, I.M., Sigsgaard, T. and Kromhout, H. (2013) Exposure to inhalable dust and endotoxin among Danish pig farmers affected by work tasks and stable characteristics. Ann. Occup. Hyg., 57(8): 1005-1019.

7. Klous, G., Huss, A., Heederik, D.J. and Coutinho, R.A. (2016) Human-livestock contacts and their relationship to transmission of zoonotic pathogens, a systematic review of literature. One Health, 2: 65-76.

8. Morse, S.S., Mazet, J.A., Woolhouse, M., Parrish, C.R., Carroll, D., Karesh, W.B., Zambrana-Torrelio, C., Lipkin, W.I. and Daszak, P. (2012) Prediction and prevention of the next pandemic zoonosis. Lancet, 380(9857): 1956-1965.

9. Plowright, R.K., Parrish, C.R., McCallum, H., Hudson, P.J., Ko, A.I., Graham, A.L. and Lloyd-Smith, J.O. (2017) Pathways to zoonotic spillover. Nat. Rev. Microbiol., 15(8): 502-510.

10. Mehndiratta, P.L. and Bhalla, P. (2014) Use of antibiotics in animal agriculture and emergence of methicillin-resistant Staphylococcus aureus (MRSA) clones: Need to assess the impact on public health. Indian J. Med. Res., 140(3): 339.

11. Rohr, J.R., Barrett, C.B., Civitello, D.J., Craft, M.E., Delius, B., DeLeo. G.A., Hudson, P.J., Jouanard, N., Nguyen, K.H., Ostfeld, R.S. and Remais, J.V. (2019) Emerging human infectious diseases and the links to global food production. Nat. Sustain., 2(6): 445-456.

12. Allen, H.K., Donato, J., Wang, H.H., Cloud-Hansen, K.A., Davies, J. and Handelsman, J. (2010) Call of the wild: Antibiotic resistance genes in natural environments. Nat. Rev. Microbiol., 8(4): 251-259.

13. Gilchrist, M.J., Greko, C., Wallinga, D.B., Beran, G.W., Riley, D.G. and Thorne, P.S. (2007) The potential role of concentrated animal feeding operations in infectious disease epidemics and antibiotic resistance. Environ. Health Perspect., 115(2): 313-316.

14. Heuer, H., Schmitt, H. and Smalla, K. (2011) Antibiotic resistance gene spread due to manure application on agricultural fields. Curr. Opin. Microbiol., 14(3): 236-243.

15. Marshall, B.M. and Levy, S.B. (2011) Food animals and antimicrobials: Impacts on human health. Clin. Microbiol. Rev., 24(4): 718-733.

16. Parisien, A., Allain, B., Zhang, J., Mandeville, R. and Lan, C.Q. (2008) Novel alternatives to antibiotics: Bacteriophages, bacterial cell wall hydrolases, and antimicrobial peptides. J. Appl. Microbiol., 104(1): 1-13.

17. Cooper, E.L. (2003) Comparative immunology. Curr. Pharm. Des., 9(2): 119-131.

18. Downs, C.J., Adelman. J.S. and Demas, G.E. (2014) Mechanisms and methods in ecoimmunology: Integrating within-organism and between-organism processes. Integr. Comp. Biol., 54(3): 340-352.

19. Metcalf, C.J., Roth, O. and Graham, A.L. (2020) Why leveraging sex differences in immune trade-offs may illuminate the evolution of senescence. Funct. Ecol., 34(1): 129-140.

20. VanderWaal, K.L. and Ezenwa, V.O. (2016) Heterogeneity in pathogen transmission: Mechanisms and methodology. Funct. Ecol., 30(10): 1606-1622.

21. Martens, E. and Demain, A.L. (2017) The antibiotic resistance crisis, with a focus on the United States. J. Antibiot., 70(5): 520-526.

22. LaPointe, D.A., Atkinson, C.T. and Samuel, M.D. (2012) Ecology and conservation biology of avian malaria. Ann. N. Y. Acad. Sci., 1249(1): 211-226.

23. Totsika, M. (2017) Disarming pathogens: Benefits and challenges of antimicrobials that target bacterial virulence instead of growth and viability. Future Med. Chem., 9(3): 267-269.

24. Schoenle, L.A., Downs, C.J. and Martin, L.B. (2018) An introduction to ecoimmunology. In: Cooper, E., editors. Advances in Comparative Immunology. Springer, Cham. p901-932.

25. Downs, C.J. and Dochtermann, N.A. (2014) Testing hypotheses in ecoimmunology using mixed models: Disentangling hierarchical correlations. Integr. Comp. Biol., 54(3): 407-418.

26. Chikeka, I. and Dumler, J.S. (2015) Neglected bacterial zoonoses. Clin. Microbiol. Infect., 21(5): 404-415.

27. Levett, P.N., Branch, S.L., Whittington, C.U., Edwards, C.N. and Paxton, H. (2001) Two methods for rapid serological diagnosis of acute leptospirosis. Clin. Diagn. Lab. Immunol., 8(2): 349-351.

28. Adler, B., Lo, M., Seemann, T. and Murray, G.L. (2011) Pathogenesis of leptospirosis: The influence of genomics. Vet. Microbiol., 153(1-2): 73-81. 
29. Verma, A. and Stevenson, B. (2012) Leptospiral uveitis-there is more to it than meets the eye! Zoonoses Public Health, 59(Supp1 2): 132-141.

30. Faisal, S.M., Varma, V.P., Subathra, M., Azam, S., Sunkara, A.K., Akif, M., Baig, M.S. and Chang, Y.F. (2016) Leptospira surface adhesin (Lsa21) induces Toll-like receptor 2 and 4 mediated inflammatory responses in macrophages. Sci. Rep., 6: 39530 .

31. Gibson, A.J. and Werling, D. (2013) Of creatures great and small: The advantages of farm animal models in immunology research. Front. Immunol., 27(4): 124.

32. Neyen, C. and Lemaitre, B. (2016) Sensing Gram-negative bacteria: A phylogenetic perspective. Curr. Opin. Immunol., 38: 8-17.

33. Priyam, M., Tripathy, M., Rai, U. and Ghorai, S.M. (2016) Tracing the evolutionary lineage of pattern recognition receptor homologues in vertebrates: An insight into reptilian immunity via de novo sequencing of the wall lizard splenic transcriptome. Vet. Immunol. Immunopathol., 172: 26-37.

34. Dumler, J.S., Barbet, A.F., Bekker, C.P., Dasch, G.A., Palmer, G.H., Ray, S.C., Rikihisa, Y. and Rurangirwa, F.R. (2001) Reorganization of genera in the families Rickettsiaceae and Anaplasmataceae in the order Rickettsiales: Unification of some species of Ehrlichia with Anaplasma, Cowdria with Ehrlichia and Ehrlichia with Neorickettsia, descriptions of six new species combinations and designation of Ehrlichia equi and 'HGE agent' as subjective synonyms of Ehrlichia phagocytophila. Int. J. Syst. Evol. Microbiol., 51(6): 2145-2165.

35. Lescot, M., Audic, S., Robert, C., Nguyen, T.T., Blanc, G., Cutler, S.J., Wincker, P., Couloux, A., Claverie, J.M., Raoult, D. and Drancourt, M. (2008) The genome of Borrelia recurrentis, the agent of deadly louse-borne relapsing fever, is a degraded subset of tick-borne Borrelia duttonii. PLoS Genet., 4(9): e1000185.

36. Fisher, C.A., Bhattarai, E.K., Osterstock, J.B., Dowd, S.E., Seabury, P.M., Vikram, M., Whitlock, R.H., Schukken, Y.H., Schnabel, R.D., Taylor, J.F. and Womack, J.E. (2011) Evolution of the bovine TLR gene family and member associations with Mycobacterium avium subspecies paratuberculosis infection. PLoS One, 6(11): e27744.

37. Bhaladhare, A., Sharma, D., Kumar, A., Sonwane, A., Chauhan, A., Singh, R., Kumar, P., Yadav, R., Baqir, M., Bhushan, B. and Prakash, O. (2016) Single nucleotide polymorphisms in toll-like receptor genes and case-control association studies with bovine tuberculosis. Vet. World, 9(5): 458.

38. Dolasia, K., Bisht, M.K., Pradhan, G., Udgata, A. and Mukhopadhyay, S. (2018) TLRs/NLRs: Shaping the landscape of host immunity. Int. Rev. Immunol., 37(1): 3-19.

39. Zheng, H., Punaro, M.C., Segura, M., Lachance, C., Rivest, S., Xu, J., Houde, M. and Gottschalk, M. (2011) Tolllike receptor 2 is partially involved in the activation of murine astrocytes by Streptococcus suis, an important zoonotic agent of meningitis. J. Neuroimmunol., 234(1-2): 71-83.

40. Ma, Z., Zhang, H., Yi, L., Fan, H. and Lu, C. (2012) Microarray analysis of the effect of Streptococcus equi subsp. zooepidemicus M-like protein in infecting porcine pulmonary alveolar macrophage. PLoS One, 7(5): e36452.

41. Bhattarai, D., Worku, T., Dad, R., Rehman, Z.U., Gong, X. and Zhang, S. (2018) Mechanism of pattern recognition receptors (PRRs) and host-pathogen interplay in bovine mastitis. Microb. Pathog., 120: 64-70.

42. Gómez, M.I. and Prince, A. (2007) Opportunistic infections in lung disease: Pseudomonas infections in cystic fibrosis. Curr. Opin. Pharmacol., 7(3): 244-251.

43. Kebede, F. (2010) Pseudomonas infection in chickens. J. Vet. Med. Anim. Health, 2(4): 55-58.

44. Yong, Y., Liu, S., Hua, G., Jia, R., Zhao, Y. Sun, X., Liao, M. and Ju, X. (2015) Identification and functional characterization of Toll-like receptor 2-1 in geese. BMC Vet. Res.,
11(1): 108 .

45. El-Seedy, F.R., Abed, A.H., Yanni, H.A. and Abd El-Rahman, S.A. (2016) Prevalence of Salmonella and E. coli in neonatal diarrheic calves. Beni-Suef Univ. J. Basic Appl. Sci., 5(1): 45-51.

46. Vazquez-Torres, A., Vallance, B.A., Bergman, M.A., Finlay, B.B., Cookson, B.T., Jones-Carson, J. and Fang, F.C. (2004) Toll-like receptor 4 dependence of innate and adaptive immunity to Salmonella: Importance of the Kupffer cell network. J. Immunol., 172(10): 6202-6208.

47. Mishra, C., Kumar, S., Panigrahi, M., Yathish, H.M., Chaudhary, R., Chauhan, A., Kumar, A. and Sonawane, A.A. (2018) Single nucleotide polymorphisms in 5'upstream region of bovine TLR4 gene affecting expression profile and transcription factor binding sites. Anim. Biotechnol., 29(2): 119-128.

48. Bilgen, N., Kul, B.C., Offord, V., Werling, D. and Ertugrul, O. (2016) Determination of genetic variations of Toll-like receptor (TLR) 2, 4, and 6 with next-generation sequencing in native cattle breeds of Anatolia and Holstein Friesian. Diversity, 8(4): 23.

49. Gupta, S.K., Deb, R., Dey, S. and Chellappa, M.M. (2014) Toll-like receptor-based adjuvants: Enhancing the immune response to vaccines against infectious diseases of chicken. Expert Rev. Vaccines, 13(7): 909-925.

50. Ghorai, S.M., Gupta, S. and Priyam, M. (2019) Unravelling the structure and protein-ligand interaction of Indo-Asian wall lizard Hemidactylus flaviviridis TLR5 (hfTLR5) via in silico approach. Int. J. Res. Anal. Rev., 6(2): 127-136.

51. Ezenwa, V.O. and Jolles, A.E. (2011) From host immunity to pathogen invasion: The effects of helminth coinfection on the dynamics of microparasites. Integr. Comp. Biol., 51(4): 540-551.

52. Rook, G.A. (2012) Hygiene hypothesis and autoimmune diseases. Clin. Rev. Allergy Immunol., 42(1): 5-15.

53. Hawley, D.M. and Altizer, S.M. (2011) Disease ecology meets ecological immunology: Understanding the links between organismal immunity and infection dynamics in natural populations. Funct. Ecol., 25(1): 48-60.

54. Christou, L. (2011) The global burden of bacterial and viral zoonotic infections. Clin. Microbiol. Infect., 17(3): 326-330.

55. Singh, R.K., Chang, H.W., Yan, D., Lee, K.M., Ucmak, D., Wong, K., Abrouk, M., Farahnik, B., Nakamura, M., Zhu, T.H. and Bhutani, T. (2017) Influence of diet on the gut microbiome and implications for human health. J. Transl. Med., 15(1): 73 .

56. Walker, A.W., Ince, J., Duncan, S.H., Webster, L.M., Holtrop, G., Ze, X., Brown, D., Stares, M.D., Scott, P., Bergerat, A. and Louis, P. (2011) Dominant and diet-responsive groups of bacteria within the human colonic microbiota. ISME J., 5(2): 220-230.

57. Noverr, M.C. and Huffnagle, G.B. (2004) Does the microbiota regulate immune responses outside the gut? Trends Microbiol., 12(12): 562-568.

58. Furet, J.P., Kong, L.C., Tap, J., Poitou, C., Basdevant, A., Bouillot, J.L., Mariat, D., Corthier, G., Doré, J., Henegar, C., Rizkalla, S. and Clément, K. (2010) Differential adaptation of human gut microbiota to bariatric surgery-induced weight loss: Links with metabolic and low-grade inflammation markers. Diabetes, 59(12): 3049-3057.

59. Ivanov, I.I., Atarashi, K., Manel N., Brodie, E.L., Shima, T., Karaoz, U., Wei, D., Goldfarb, K.C., Santee, C.A., Lynch, S.V., Tanoue, T., Imaoka, A., Itoh, K., Takeda, K., Umesaki, Y., Honda, K. and Littman, D.R. (2009) Induction of intestinal Th17 cells by segmented filamentous bacteria. Cell, 139(3): 485-498.

60. Trompette, A., Gollwitzer, E.S., Yadava, K., Sichelstiel, A.K., Sprenger, N., Ngom-Bru, C., Blanchard, C., Junt, T., Nicod, L.P., Harris, N.L. and Marsland, B.J. (2014) Gut microbiota metabolism of dietary fiber influences allergic airway disease and hematopoiesis. Nat. Med., 20(2): 159-166. 
61. Mandal, S.M., Roy, A., Ghosh, A.K., Hazra, T.K., Basak, A. and Franco, O.L. (2014) Challenges and future prospects of antibiotic therapy: From peptides to phages utilization. Front. Pharmacol., 5: 105.

62. Gutiérrez, D., Fernández, L., Rodríguez, A. and García, P. (2018) Are phage lytic proteins the secret weapon to kill Staphylococcus aureus? Mbio, 9(1): 1-17.

63. Safir, M.C., Bhavnani, S.M., Slover, C.M., Ambrose, P.G. and Rubino, C.M. (2020) Antibacterial drug development: A new approach is needed for the field to survive and thrive. Antibiotics, 9(7): 412.

64. Fowler, V.G.Jr., Das, A.F., Lipka-Diamond, J., Schuch, R., Pomerantz, R., Jáuregui-Peredo, L., Bressler, A., Evans, D., Moran, G.J., Rupp, M.E., Wise, R., Corey, G.R., Zervos, M., Douglas, P.S. and Cassino, C. (2020) Exebacase for patients with Staphylococcus aureus bloodstream infection and endocarditis. J. Clin. Investig., 130(7): 3750-3760.

65. Schmelcher, M., Donovan, D.M. and Loessner, M.J. (2012) Bacteriophage endolysins as novel antimicrobials. Future Microbiol., 7(10): 1147-1171.

66. Young, R. (2013) Phage lysis: Do we have the hole story yet? Curr. Opin. Microbiol., 16(6): 790-797.

67. Wang, I.N., Smith, D.L. and Young, R. (2000) Holins: The protein clocks of bacteriophage infections. Ann. Rev. Microbiol., 54(1): 799-825.

68. Morello, E., Saussereau, E., Maura, D., Huerre, M., Touqui, L. and Debarbieux, L. (2011) Pulmonary bacteriophage therapy on Pseudomonas aeruginosa cystic fibrosis strains: First steps towards treatment and prevention. PLoS One, 6(2): e16963.

69. Broxmeyer, L., Sosnowska, D., Miltner, E., Chacón, O., Wagner, D., McGarvey, J., Barletta, R.G. and Bermudez, L.E. (2002) Killing of Mycobacterium avium and Mycobacterium tuberculosis by a mycobacteriophage delivered by a nonvirulent Mycobacterium: A model for phage therapy of intracellular bacterial pathogens. J. Infect. Dis., 186(8): 1155-1160.

70. Styles, K.M., Thummeepak, R., Leungtongkam, U., Smith, S.E., Christie, G.S., Millard, A., Moat, J., Dowson, C.G., Wellington, E.M.H., Sitthisak, S. and Sagona, A.P. (2020) Investigating bacteriophages targeting the opportunistic pathogen Acinetobacter baumannii. Antibiotics, 9(4): 200.

71. Kang, S.J., Kim, D.H., Mishig-Ochir, T. and Lee, B.J. (2012) Antimicrobial peptides: Their physicochemical properties and therapeutic application. Arch. Pharm. Res., 35(3): 409-413.

72. Riley, M.A. and Wertz, J.E. (2002) Bacteriocins: Evolution, ecology, and application. Ann. Rev. Microbiol., 56(1): 117-137.

73. Fernebro, J. (2011) Fighting bacterial infections future treatment options. Drug Resist. Updat., 14(2): 125-139.

74. Miki, T. and Hardt, W.D. (2013) Outer membrane permeabilization is an essential step in the killing of Gram-negative bacteria by the lectin RegIII $\beta$. PLoS One, 8(7): e69901.

75. Monteiro, D.R., Gorup, L.F., Takamiya, A.S., RuvolloFilho, A.C., de Camargo, E.R. and Barbosa, D.B. (2009) The growing importance of materials that prevent microbial adhesion: Antimicrobial effect of medical devices containing silver. Int. J. Antimicrob. Agents, 34(2): 103-110.

76. Verderosa, A.D., Totsika, M. and Fairfull-Smith, K.E. (2019) Bacterial biofilm eradication agents: A current review. Front. Chem., 7: 824.

77. Nishiura, H., Hoye, B., Klaassen, M., Bauer, S. and Heesterbeek, H. (2009) How to find natural reservoir hosts from endemic prevalence in a multi-host population: A case study of influenza in waterfowl. Epidemics, 1(2): 118-128.

78. Taubenberger, J.K. and Morens, D.M. (2010) Influenza: The once and future pandemic. Public Health Rep., 125(3): 16-26.

$* * * * * * * *$ 